\title{
A Study of the Methods of Chinese New Words Rhetoric Word Building
}

\author{
Liping Wang \\ Weifang University of Science and Technology \\ Shou Guang, 262700, China
}

\begin{abstract}
The article main research of the formation of Chinese new words rhetorical ways. First analyzes the basic situation of the "word" rhetoric, and definition and principles of new words, and then study and discuss all kinds of rhetoric formation emphatically, including made lexical metaphor, metonymy formation and lexical parody. Analyse the characteristics and trends of new words constituted by parody, metaphor, metonymy at last.
\end{abstract}

Keywords-Rhetoric; New words; Metaphor; Metonymy; Parody

\section{INTRODUCTION}

New words new threads are to observe a barometer of social life, are a mirror of the real. In the transition period of Chinese society, its colorful humanities landscape. After the reform the door opens, gush to a foreign culture. Domestic foreign culture collide with each other, each other mutual communion, mutual penetration, produced a number of times to change new word jargons.

\section{THE DEFINITION AND PRINCIPLES OF THE NEW} WORDS

Language and social structure under the covariant form, it is the great changes in society since the reform and opening up, that is growing at year thousands of new words. New words are a new creation or other languages, from the national dialect words, the old saying words and borrowed words in the word, also means a new meaning and a new use of the inherent.

\section{A. Necessity principle}

The emergence and development of new words must have the need of actual expression, by most people in the process of authentic communication need words. New words is to reflect the new things, new concept and form, some appellation new things, new phenomena, such as: "the space cotton, jelly, commodity house, Internet cafes, goods, card", etc.; Make simple language of the new words, such as the basic, 10, color TV "and so on. In the process of exchanges between Chinese and other language, other languages into Chinese internal influence Chinese vocabulary, make Chinese positive or negative to the introduction of some foreign words to create new words, such as "burger, software, hardware," and other words.

\section{B. The principle of clarity}

So-called "certainty" is to express the meaning of different words to clear and understandable, accepted by most people. Only in line with the clear, new words can be spread widely, rooted in our language, such as: "foreign microclimate, group, joint venture" and other words.

\section{The stability principle of}

Formed by these latest words in modern society, only a relatively stable, in order to have the possibility of recognition from society. Words such as "awareness, fired, and widely applied in society, thus obtaining stability, became the original words.

\section{Habitual principle}

The product of our language itself is established. As a result, additional words must be expressed by the social habits. And habitual principles have to conform to the social and cultural habits and the psychological habits.

To sum up, the above defines the scope of new words and specific principles. And between these principles are interdependent and complementary. Understanding of new words, which is beneficial to lead us to correctly understand and use the motherland 
language, promotes the standardization of the language specification. Have a correct understanding of new words is a very important significance to the standardization of the vocabulary system, is the important content of socialist spiritual civilization construction in our country, is also the need of the social development.

\section{MADE LEXICAL METAPHOR}

"Metaphor": metaphor is figuratively, is in essence different have similarities things depict things or say how reasonable words, also called "parables". Metaphor is something called "ontology", for instance, used to, for something called "metaphors", contact the two words is called "your work".

Structurally, the new words in the new using the metaphor of this kind of figures of speech, generally has the following categories:

\section{A. With metaphors as modifier,}

word ontology category as a center, make new words. This kind of new metaphors is generally has the characteristics of an image vivid and easy to understand. Take a focal point of Pi varied also, its outstanding way is to make the language concise and lively. Such as: Grassroots industry: refers to is embedded in the rural land development of township enterprises. Can drive the leading global enterprises, as a leading and other advances and the development of the enterprise.

\section{B. As metaphors for ontology, that is, give new than the inter-cultural to certain words.}

In this type of words, would have been by some ordinary words, such as the "mother", "window" and "fist"; Some was professional, trade terms, such as the "green light", "yellow card", as new words, they have been given a new than the inter-cultural use scope has been broadened. And some new words also can be invoked as a combining form, form new words. Such as: climate, climate microclimate nova: tennis star movie star Parnassus nova in the "window", "leading" and "fist" and said the first kind of closure or formed by (1) class omit a generic term of ontology. Language such as "leading" according to some researchers, first appeared in newspapers and magazines "leading products", "leading enterprise" and other phrases, then a "tap" on a single use. Such as: "leader" of science and technology is abundant. Metaphors used alone or come first, and then extended to a class of words, like "window", for example: commercial, service and transportation department is the window of collective civilization fashion. Creating the industry always referred to as the "window industry". These two types of words there is one thing in common that the "window", "dragon" in the spoken language, words such as "first" metaphor is already existing, after when they enter the written language, was soon by extension.

\section{Word metaphors as the center,}

the front and a series of modify, restrict ingredients, make new words. Center words of two syllables, also have a single syllable.

D. Some new words, from start to use it, just as a figurative use. Such as:

Pot: refers to is not in accordance with the socialist distribution principle of egalitarian distribution system.

One size fits all. Refers to that kind of not discriminate according to the actual condition of simple methods of work.

This kind of words is quite literally, this refers to a kind of phenomenon or things, only few people use their literal meaning, but the commonly used them to refers to a certain things and phenomena, in the process of using this kind of words with the meaning of some conventional step by step.

\section{METONYMY FORMATION}

"Metonymy": don't say the name of the person or something, closely related to its name to replace, this word is called metonymy, also called "change". Such as "red scarf" instead of young pioneers. Instead of something called "ontology", used instead of something called "borrow". 
Use metonymy rhetorical form new words, in general can be divided into the following categories:

\section{A. To the said generation refers to the known.}

Originally, such as: bold, had you in "the horse said" names, good at horse later generation refers to good at finding talent recommendation talented person. Silicon valley: originated in the United States, the electronic industrial base, the modern electronics industry base.

B. In a related stuff for one thing. Such as:

Red envelopes: Generation, it is the parents give the gratuity or factories and mines, enterprises and institutions of the people of the younger generation to employee bonuses.

\section{As a characteristic part of our tag generation} refers to the things. Such as:.

Unity: relates to the of the face value of the yuan $\mathrm{RMB}$, because the patterns of the printed with national unity.

\section{With characteristic behavior generation refers to} something. Such as:

Draw a circle: Generation refers to read and circle the file. Some leading comrades in reading or instructions files, often circle said have a look..

\section{E. With vivid appellation generation refers to the original proper noun. Such as:}

Iron Hammer: lang ping spiking ferocious strength, "lang" and "Lang" homonym, people on the "iron hammer" for lang ping.

\section{F. With proper noun generation refers to the proper noun or reflect the kind of social phenomenon, concept, etc.}

Such as: "silver phenomenon" refers to the leading cadres at the bad social phenomenon put. "Star Power" means a star in the field of literature and art, sports, etc as a result of states of attraction and appeal of a social phenomenon. This kind of words from sense, there's a certain fuzziness and randomness; In structure, stand in the structure; It is different from general rhetoric on metonymy in "proper noun to collectively", from the whole phrase, is only part of metonymy.

\section{MADE LEXICAL PARODY}

Parody technique is adopted to form new words. Actually contains two different situations: one is for the purpose of rhetoric in the specific language environment, the use of parody and the new accidental words. This kind of new words

\section{A. The format of copy.}

Some of Chinese vocabulary words to form the frame structure is obvious in form, this kind of frame structure is composed of a class of words format, according to a certain format, through changing certain formative, can produce a series of words with the format. "Format copy" is through parody vocabulary system in this kind of method of the typical format and form new words.

\section{B. Semantic imitation.}

Semantic imitation is using words semantically exist between relations such as justice, of righteousness, antigens to parody of word-formation.

C. On the basis of whether or not the only means to differentiate "parody, can be divided into pure type and combination type.

\section{CHARACTERISTICS AND TRENDS OF RHETORICAL}

\section{WAY OF NEW WORD}

\section{A. The characteristics of the rhetoric form new words}

First of all, this kind of word with era characteristics. This kind of word is more vivid, enhanced the expressive force of Chinese and enrich the Chinese vocabulary. New words neologisms have come about in recent decades. There is a modern tendency to seek elegant and seriation, also show the image is bright, popularization, colloquial momentum

Secondly, the meaning of these words is fuzzy. the ambiguity of word meaning is refers to the concepts they 
express extension of the lack of clear boundaries, formed by metaphor and metonymy of solidification of new words and their meaning is widespread rather vague.

Again, rhetoric words often has the characteristics of temporary, this kind of words to reflect the objective things themselves quite a most temporary or short-term social thing and phenomena.

\section{B. The development of the new words in the composition of rhetoric}

First of all, the general trend of a rhetorical way to constitute new words is increasingly enriched and expanded. It makes the language of some form is preserved at the same time, and added new content, make the words more full of vitality, more characteristics of The Times. Is the basic way for people to pursue simple and efficient communication conforms to the general trend of vocabulary?

Second, most unfamiliar words formed by metaphor and metonymy, the vast majority of word meaning is vague, may be other words instead of in the expression. So new words have limitations in use, make them into conventional words under the influence of different degree.

Again, as a result of these original words used in spoken language, more can't enter the documents, scientific papers and other genres.

In the end, most new words to express a variety of mixed feelings, and emotions, and often influenced by all kinds of social environmental factors. From on the whole: different words spread by certain limits, into general words may be relatively small. Have relatively temporary, only a few words can enter the general words and have relative stability?

\section{The characteristics of the new words and trend in the composition of metaphor and metonymy}

Composed of metaphor and metonymy rhetoric way new words has some remarkable characteristics. First of all, this kind of word with era characteristics. In rhetoric and gradually solidified into new words, it is a natural phenomenon in the development of Chinese vocabulary. New words new threads have sprung up in recent decades, there is a modern tendency to seek elegant and seriation, also show the image is bright, popularization, colloquial momentum. Now is the era of the era, the personality is respected, human value, the creation of personal spirit has been advocated, protect and carry forward, in the words by metaphor and metonymy produced no less than personal proper noun related words. Today's era is also a rapidly changing social economy rapid development, science and technology information, and thus be used to do borrow body or metaphors for more things in the field of economy, culture, science and technology, such as: "shaggymane", "silicon valley". This change reflects the profound changes of social life in China today, as well as the critical transfer center in the view of the broad masses. Secondly, the meaning of these words is fuzzy. the ambiguity of word meaning is refers to the concepts they express extension of the lack of clear boundaries, formed by metaphor and metonymy of solidification of new words and their meaning is widespread rather vague. Some rhetoric can form new words, different meanings of their lifespan is short is long, mainly depend on the condition of the people use this statement, namely the established. This kind of word in general is temporary, only a few words can enter the general words, maintain the long-term stability.

\section{Characteristics and trends of parody of neologisms}

Composed of parody new words exactly have that characteristic. Parody type new words with the correspondence. Parody of new words and the corresponding relationship between prototype words. Type of new words in class, "parody of righteousness and antagonise relations constitute the semantics of the imitation of new words is the prominent manifestation of correspondence. Parody phenomenon is the inevitable outcome of the collective development and fast-paced life. People use language systems of some existing component to express their understanding and thinking 
activity of new achievements, thus produced the new words. Parody of the generated additional words can be smoothly into the modern Chinese vocabulary to see if it conforms to the rule of word formation, is in line with the language habits of the masses. Parody of the positive effect is the primary, but blindly imitate will also have a negative effect. In recent years, some people in order to do sth unconventional or unorthodox, or in order to achieve a certain purpose, especially some advertising media, ignoring the language rule, make use of homophonic careless word creation. However, overall, the parody can produce strong sex, vitality is strong, its positive role is the main, it conforms to the general trend of vocabulary.

\section{CONCLUSION}

The use of figures of speech to form new words new semantic metaphor, metonymy, parody, the most common of course composed of other rhetoric may also not allow to ignore to new words. Harmonics of unfamiliar words, grandiose also a lot of new words, and there is new meaning the direct meaning of new words. All of these further illustrate the "word" rhetoric is completely feasible, and it is worthy of study in linguistics an interesting phenomenon.

\section{REFERENCES}

[1] Xiaoli Yang.Parody type new words w.k.che man the rhetoric study 5, 1993.

[2] Lanmin Liu.Chinese imitation word coinage type series.the 2001, 2.

[3] Xuzhu Wang. The design process of a graphic designer, Beijing, China Youth publishing house, 1999.

[4] Guosheng Lin. The existence of the extraction of Chinese characters symbolic value and competitive advantage, 2001.8.

[5] Xigang Zhao. "modern graphic design and traditional design" (" the decoration ", 2003, 4.

[6] Ruilin Chen. "The history of Chinese modern art design," human science and technology publishing house.

[7] Yanzu Li, "the history of visual communication design and aesthetics", the Chinese people's university press, 2000.

[8] Yucheng Lu. The auspicious concept in the traditional decorative pattern and modern design, 2004.1.

[9] Yanping Qi.Metaphor, metonymy, and the construction of Chinese new words and new use in 1989 no. 4.

[10] Hongxi Liu.Chinese new words generated parody phenomenon in Journal of YuZhou University in 1999, no. 4.

[11] Tiekun Wang.Look at the reflection on the emergence and development of new meanings of new words "Journal of tianjin normal university, 1987, 2. 